\title{
The design of super long span pedestrian landscape cable stayed bridge with sightseeing bridge tower
}

\author{
Tao Jiang ${ }^{1}$ and BiQing $\mathrm{Li}^{1 *}$ \\ ${ }^{1}$ Jiangsu Southeast Special Technical Engineering Co., Ltd, Nanjing, China,210008
}

\begin{abstract}
According to the design requirements of the super long-span pedestrian landscape cable-stayed bridge in Lake view Park, a kind of sightseeing tower-style pedestrian landscape three-tower cable-stayed bridge structure system was proposed. Sightseeing tower type bridge tower structure and duck egg arched bridge tower replace traditional cable-stayed bridge tower structure. Through the establishment of Midas finite element analysis model, dynamic modal analysis research was carried out. The analysis shows that: the sightseeing tower structure and the cable-stayed bridge tower structure are combined into one, and the two have good structural matching.
\end{abstract}

\section{Introduction}

With the development of the times, more and more people like to visit the Lake View Park. The sightseeing tower buildings and Landscape Bridges of the Lake View Park are also becoming increasingly important ${ }^{[1-2]}$. It is necessary to coordinate the two basic needs of the traffic bridge and the sightseeing tower in the scenic area ${ }^{[3-5]}$. It integrates the sightseeing tower building and landscape bridge in one, complementing each other in function, forming the landmark characteristic building of Lake View Park, and enriching the cultural connotation of the scenic spot ${ }^{[7-8]}$.

The traditional portal pylon structure of cable-stayed bridge is reformed. The sightseeing tower type pylon structure and duck egg shaped arch pylon are used as pylon structure of cable-stayed bridge. The pedestrian landscape three pylon cable-stayed bridge of Lake View Park is built, killing two birds with one stone, forming a super long span pedestrian landscape three pylon cablestayed bridge based on sightseeing tower type pylon structure.

In this paper, combined with the design of the super long span pedestrian landscape cable-stayed bridge of a lake view park, the structural configuration of the pedestrian landscape cable-stayed bridge with tower structure is studied, the engineering parameters are designed, the Midas finite element analysis model is established, and the internal force analysis and dynamic modal analysis under vertical load are carried out, so as to verify the sightseeing tower structure and cable-stayed bridge The matching rationality of the structure.

\section{Research on geometric configuration}

The ecological landscape pedestrian cable-stayed bridge in lake view park is a three tower cable-stayed bridge structure. The middle tower adopts the sightseeing tower tower tower structure of single leaf hyperboloid shape, and the two sides of the bridge tower structure adopt duck egg arch bridge tower.

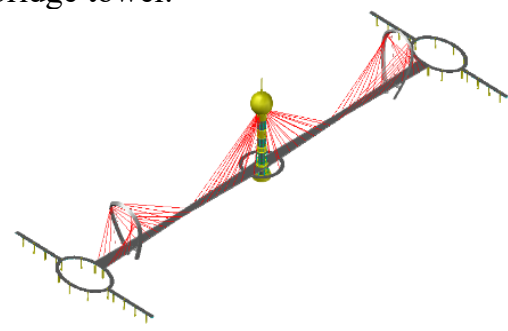

Figure 1. 3D drawing

The traditional three pylon cable-stayed bridge has no auxiliary transition piers on both sides of the middle pylon, which makes the cable-stayed bridge with flexible single column tower structure more flexible. The live load deflection of the main beam in the middle span of the three tower cable-stayed bridge is much larger than that of the conventional cable-stayed bridge. Therefore, the sightseeing bridge tower with higher structural stiffness is adopted in the middle tower of the design, which can greatly improve the vertical stiffness, reduce the live load deflection of the main beam in the middle span, meet the functional requirements of landscape and structural safety, and kill two birds with one stone.

Multiple stay cables are anchored to the top of the tower structure and duck egg arch structure in batches, and the two sides of variable cross-section elliptical arc single box and double chamber concrete box girder structure are suspended by multiple cables in batches.

\footnotetext{
*Li Biqing: umabank@163.com
} 
A giant circular concrete curved beam is set around the tower structure of the sightseeing tower, which is also used as a pedestrian sightseeing platform.

The pedestrian landscape cable-stayed bridge and the sightseeing tower share the same tower body and foundation, which greatly saves the investment in the reconstruction and construction of Lake View Park, and has remarkable economic benefits.

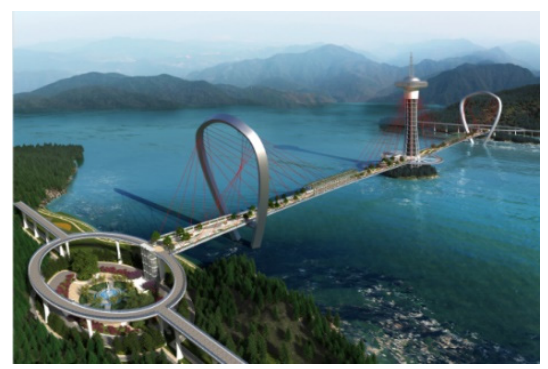

Figure 2. Effect Drawing

The sightseeing tower and the cable-stayed bridge tower are in one, with complementary functions, novel shapes and rich facades, which enhance the aesthetic effect of pedestrian landscape bridges. The curve structures of small waist-shaped sightseeing tower with single leaf hyperboloid shape, duck egg arch bridge tower and single leaf hyperboloid variable cross-section elliptical arc single box and double chamber concrete box girder structure complement each other and complement each other Beautiful and graceful.

\section{3 parameter design}
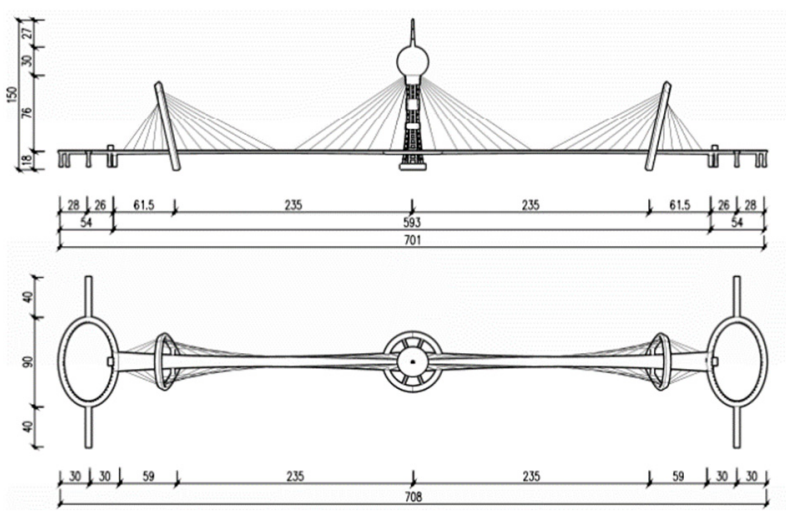

Figure 3. overall design

The main span of the three-tower cable-stayed bridge in a long-span pedestrian landscape in a lakeside park is $80 \mathrm{~m}$ $+2 \times 240 \mathrm{~m}+80 \mathrm{~m}$. The middle bridge tower is a sightseeing tower structure with a single lobed hyperboloid shape, the two sides of the bridge tower are arched duck eggs, and the deck structure is a concrete box girder structure with variable section elliptic single box and double chamber.

The tower height of sightseeing cable-stayed bridge is $100.5 \mathrm{~m}$. The tower structure is composed of sightseeing tower base, sightseeing tower body and sightseeing tower top. The height of sightseeing tower base is $5.5 \mathrm{~m}$ reception hall. The sightseeing tower body is a $75 \mathrm{~m}$ high single leaf hyperboloid tube in tube structure. The top of sightseeing tower is an inverted conical shell steel tower top with a height of $20 \mathrm{~m}$.

The bottom of sightseeing tower type bridge tower adopts pile foundation, and the tower body adopts tube in tube structure of internal reinforced concrete core tube and external concrete-filled steel tube frame tube. The internal reinforced concrete core tube is equipped with spiral stairs and a circular elevator, and the inner cylinder diameter is 12 meters; the external steel tube concrete frame tube adopts single leaf hyperboloid shape, the outer tube diameter is 12-24 meters, and the frame tube is vertical The column is composed of eight hyperbolic concrete-filled steel tubular columns with a diameter of 1.4 meters and a wall thickness of $25 \mathrm{~mm}$. The steel ring beam is connected with eight hyperbolic concrete-filled steel tubular columns. The steel ring beam is $900 \mathrm{~mm}$ in diameter, $16 \mathrm{~mm}$ in wall thickness and $6 \mathrm{~m}$ in spacing between steel ring beams, forming a single leaf hyperboloid shape. The external concrete-filled steel tube frame tube is built in the inner and outer reinforced concrete core tube The concrete-filled steel tube frame tube is provided with multiple diaphragms with a spacing of 18 meters.

The Arch Tower of duck egg on both sides is composed of the top of parabola section and two columns with left and right elliptic arc sections. The highest part of the tower is 65 meters, the widest part of the tower is 40 meters, of which the width of the tower top of parabola section is 32 meters, the arch height is 7 meters, the height of the tower column in the elliptic arc section is 58 meters, the duck egg arch bridge tower adopts the square steel pipe with the side length of $5 \mathrm{~m}$, the steel pipe wall thickness is $18 \mathrm{~mm}, \mathrm{C} 40$ concrete is poured in the inner part, and the duck egg arch is used The pile foundation is adopted for the shaped bridge tower with an inclination angle of $24^{\circ}$.

The variable cross-section elliptical arc single box double chamber concrete box girder structure is a half single leaf hyperboloid shape, one end is fixed in the tower body of the sightseeing tower, and the other end is placed on the duck egg shaped arch bridge tower body. The width of the bridge surface of the variable crosssection elliptical arc single box double chamber concrete box girder is 10-20 meters, the beam height is $2.5-4$ meters, the section shape is elliptical arc box girder structure, and the top plate thickness of the concrete box girder is 250 The thickness of elliptical arc-shaped bottom plate of concrete box girder is $200-300 \mathrm{~mm}$, the middle longitudinal web plate is corrugated steel web, and the diaphragms are reinforced concrete structure diaphragms, and the spacing between diaphragms is $60 \mathrm{~m}$.

The variable cross-section elliptical arc single box double chamber concrete box girder structure is a half single leaf hyperboloid shape, one end is fixed in the tower body of the sightseeing tower, and the other end is placed on the duck egg shaped arch bridge tower body. The width of the bridge surface of the variable crosssection elliptical arc single box double chamber concrete box girder is 10-20 meters, the beam height is $2.5-4$ meters, the section shape is elliptical arc box girder structure, and the top plate thickness of the concrete box girder is 250 The thickness of elliptical arc-shaped bottom 
plate of concrete box girder is $200-300 \mathrm{~mm}$, the middle longitudinal web plate is corrugated steel web, and the diaphragms are reinforced concrete structure diaphragms, and the spacing between diaphragms is $60 \mathrm{~m}$. The span arrangement of the three tower cable-stayed bridge in this design is $80 \mathrm{~m}+2 \times 240 \mathrm{~m}+80 \mathrm{~m}$ unequal span cablestayed bridge, and the side span is asymmetric cablestayed bridge. The structural treatment methods are as follows: adopting variable cross-section and variable cross-section elliptical arc-shaped single box and double chamber concrete box girder structure to reduce the dead weight of mid span load; adopting inclined duck egg arch bridge tower, carrying out side span counterweight and adding side span ground anchor cable In order to adjust the unbalanced internal force of the side tower structure, the steel-making slag with a height of $0.8 \mathrm{~m}$ is filled in the stiffening beam of the $80 \mathrm{~m}$ side span concrete box girder.

There are 2 spans $\times 18$ pairs of steel wire cables in the whole bridge. There are 7 pairs of cables on the left and right sides of the sightseeing bridge tower in the middle. The steel wire cables are $0.25 \mathrm{~m}$ high-strength steel wire cables with a spacing of $15 \mathrm{~m}$. There are 7 pairs of cables inside the left and right duck egg shaped arch bridge towers, and the steel wire cables are $0.25 \mathrm{~m}$ high-strength steel wire cables with a spacing of $15 \mathrm{~m}$. The outer sides of the two duck egg shaped arch bridge towers are four pairs of twisted back cables and steel cables The diameter of the cable is $0.3 \mathrm{~m}$, and the cable spacing is $20 \mathrm{~m}$. The prefabricated parallel strand method (PPWS method) is adopted for the parallel steel wire cable, and 1770mpa $\varphi$ $5.2 \mathrm{~mm}$ high-strength steel wire is used.

Midas finite element model of bridge structure is shown in the figure below.

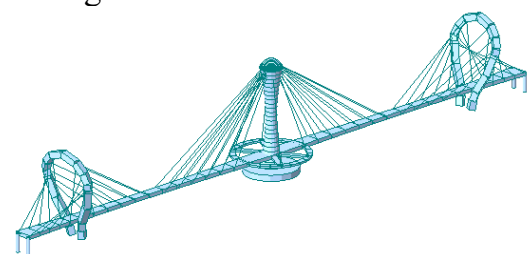

Figure 4. Midas finite element model

The center diameter of the giant circular concrete curved beam is 60 meters, the width of the giant circular concrete curved beam is 6 meters, and the beam height is 2.5 meters. The single box and single cell elliptical arc concrete box girder structure is adopted. The thickness of the concrete box girder top plate is $200 \mathrm{~mm}$, and the thickness of the elliptical arc bottom plate of the concrete box girder is $160 \mathrm{~mm}$.

The giant circular concrete curved beam is anchored on the top of the sightseeing tower by eight high-strength steel wire cables with a diameter of $0.2 \mathrm{~m}$. Six concrete tie beams are set between the giant circular concrete curved beam and the tower body to prevent the lateral deformation of the giant circular concrete curved beam.

\section{Calculation results under vertical load}

Considering that the stiffness of the middle span girder of the three tower cable-stayed bridge is the key problem in the design of the bridge, the structural calculation of the bridge is carried out under two load cases: the full span live load and the disadvantageous layout live load. The calculation results under vertical load are as follows:

(1) Full span live load case

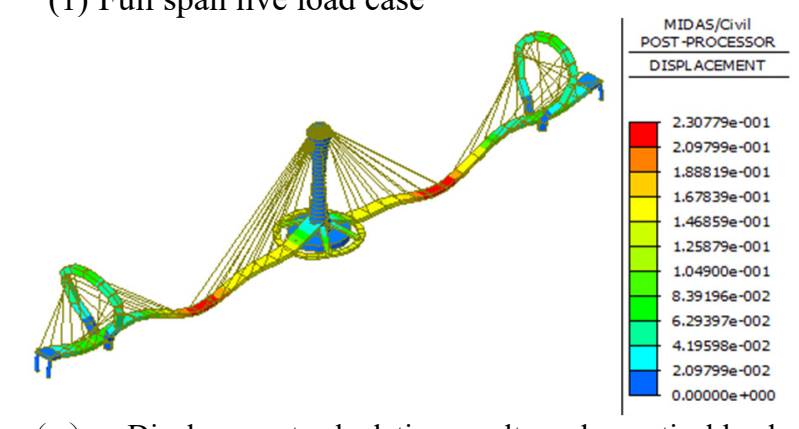

(a) Displacement calculation results under vertical load

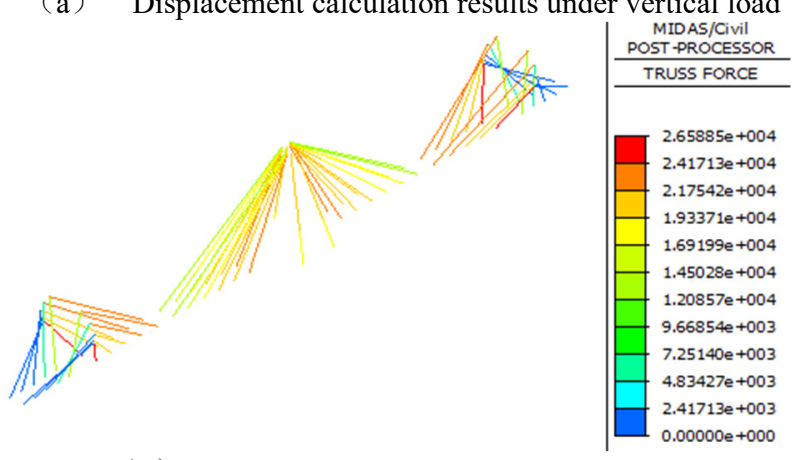

(b) Cable internal force calculation results

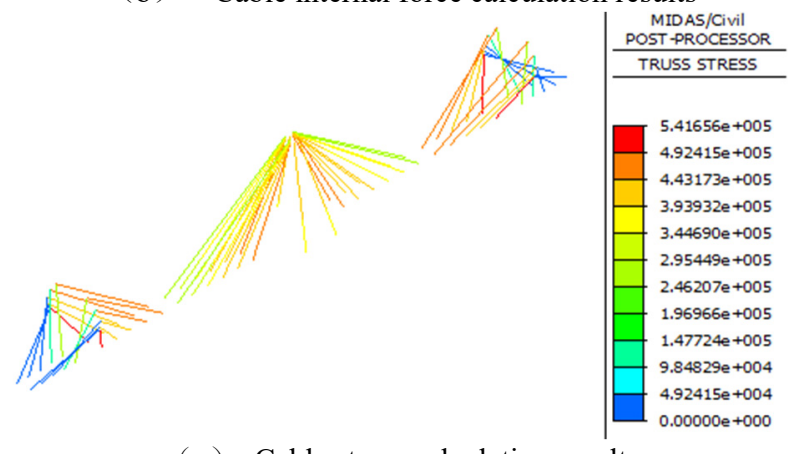

(c) Cable stress calculation results

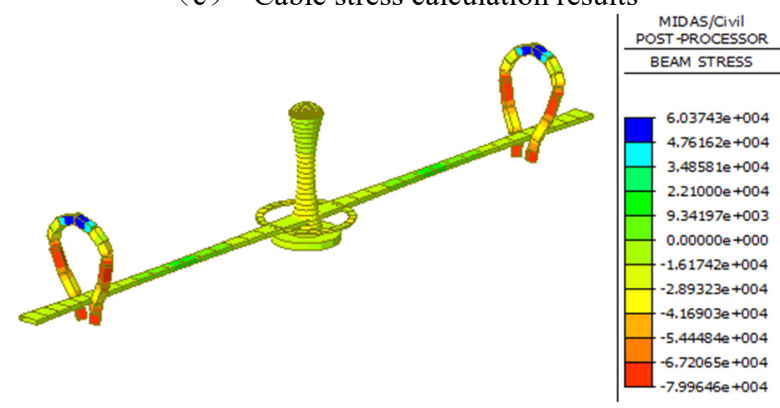

(d) Stress of tower beam element

Figure 5. calculation results of full span live load (dead + Live)

It can be seen from the above calculation results that the maximum vertical displacement occurs in the middle of the span, and the vertical deflection under the vertical live load is $0.231 \mathrm{~m}$, which meets the requirement of $1 /$ 500 limit specified in the code.

The maximum internal force of the cable is $26588.5 \mathrm{kn}$, and the maximum stress of the cable is $541.7 \mathrm{mpa}$, which meets the strength requirements.

The maximum stress of tower beam element is $79.9 \mathrm{mpa}$, which meets the strength requirements. 
(2) Considering the unfavorable layout condition of live load
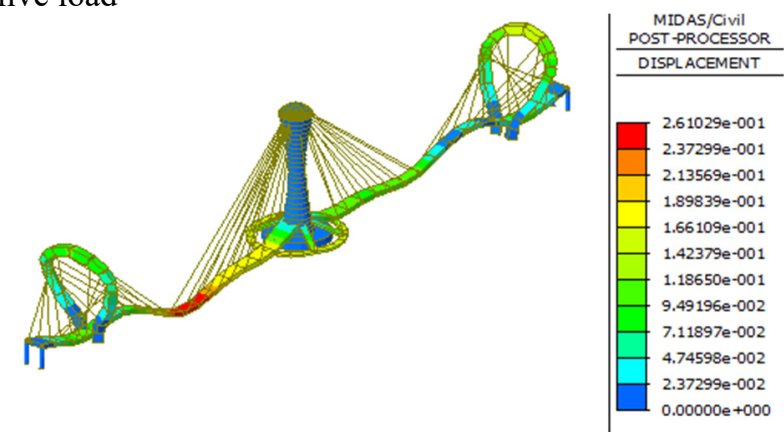

(a) Displacement calculation results under vertical load

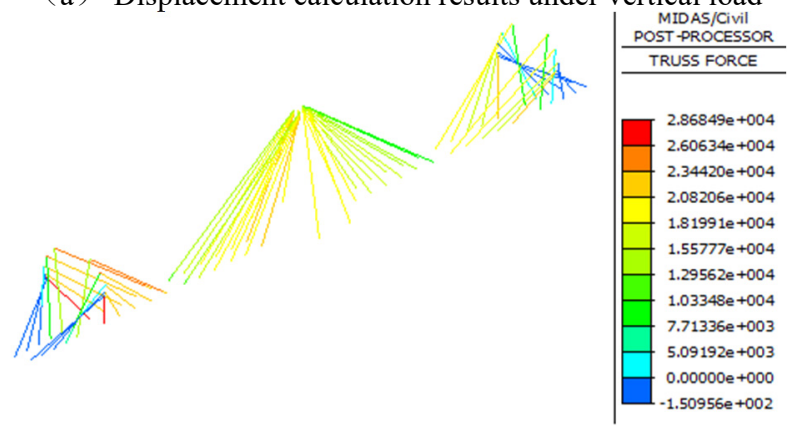

(b) Internal force of cable

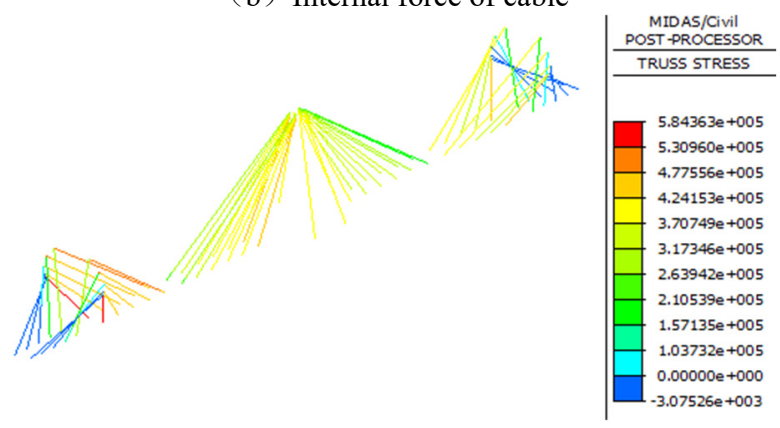

(c) Cable stress

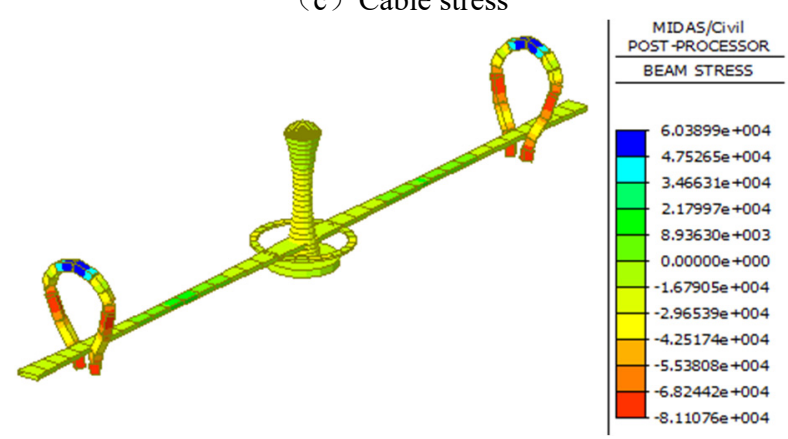

(d) Beam element stress

Figure 6. calculation results of unfavorable live load cases (dead+ Live)

From the above calculation results, it can be seen that the maximum vertical displacement of the bridge deck under the adverse layout live load (only the right one span is arranged with live load) occurs in the middle of the span, and the vertical deflection under the vertical live load is $0.261 \mathrm{~m}$, which meets the $1 / 500$ limit specified in the code.

The bridge deck without live load (the right one span) has a $0.105 \mathrm{~m}$ upward inverted arch deformation in the middle of the span.

The lateral displacement of the middle tower is $0.018 \mathrm{M}$, which meets the requirements of the code. The inclination ratio of the tower top after bending is $0.024 \%$, which meets the requirements of the regulations. It shows that the tower stiffness of the sightseeing tower type bridge in the middle is large, which can avoid the weak tower structure problem of the single column middle tower of the three tower cable-stayed bridge.

The maximum internal force of the cable is $28684.9 \mathrm{kn}$, and the maximum stress of the cable is $584.4 \mathrm{mpa}$, which meets the strength requirements.

The maximum stress of the tower beam element is $81.1 \mathrm{mpa}$, which meets the strength requirements.

There is no auxiliary transition pier on both sides of the middle pylon of the three tower cable-stayed bridge, which lacks the constraint help of the main beam and the cable tower stiffness, which makes the cable-stayed bridge with flexible single column tower structure more flexible. The live load deflection of the main beam in the middle span of the three tower cable-stayed bridge is much larger than that of the conventional cable-stayed bridge.

The key to the smooth implementation of the single column three tower cable-stayed bridge with weak tower structure is how to solve the stiffness problem of the main beam of the middle span. Therefore, the sightseeing bridge tower with larger structural stiffness is adopted in the design of the middle tower, which can greatly improve the vertical stiffness and effectively reduce the midspan deflection of the main beam of the middle span under the adverse live load. The combination of the sightseeing tower structure and the tower structure of the cable-stayed bridge Two for one, the two have good structural matching.

\section{Modal calculation results}

The main cable is the main load-bearing structure of cable-stayed bridge, and the internal force of main cable and sling is included in the form of initial tension in dynamic characteristic analysis and modeling. Based on Midas's nonlinear static analysis and modal analysis function, the natural vibration characteristics are analyzed. In order to avoid omitting any vibration mode, the sub block method is used to solve the characteristic equation.

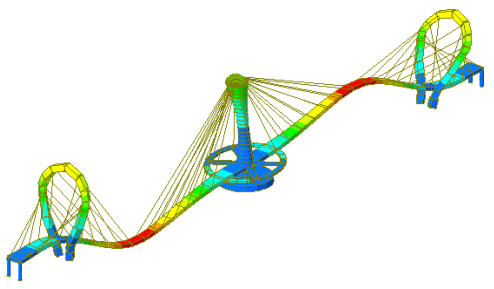

(a) 1st mode shape (antisymmetric vertical bending) $(0.587 \mathrm{hz})$

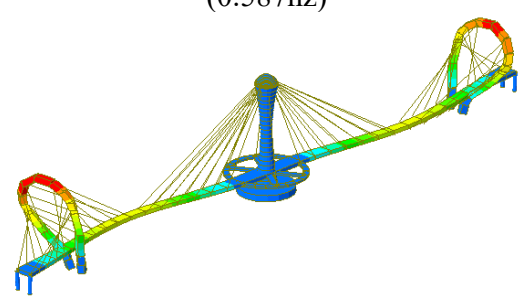

(b) 2nd mode shape (antisymmetric lateral bending of duck egg arch) $(0.596 \mathrm{~Hz})$ 


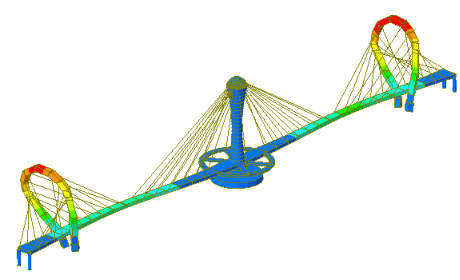

(c) 3rd order mode shape (duck egg arch positive symmetrical lateral bending) $(0.603 \mathrm{hz})$

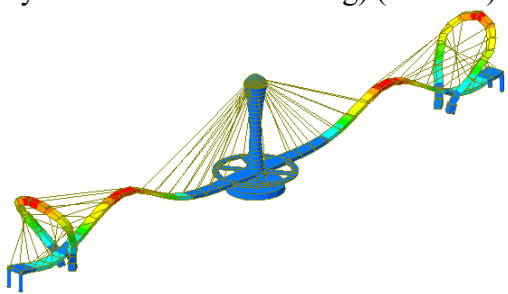

(d) 4th mode shape (positive symmetrical vertical bending) (0.640hz)

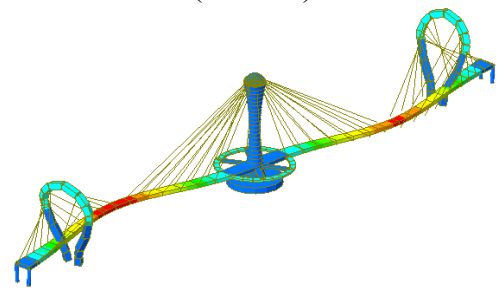

(e) 5th mode shape (antisymmetric lateral bending) $(0.647 \mathrm{hz})$

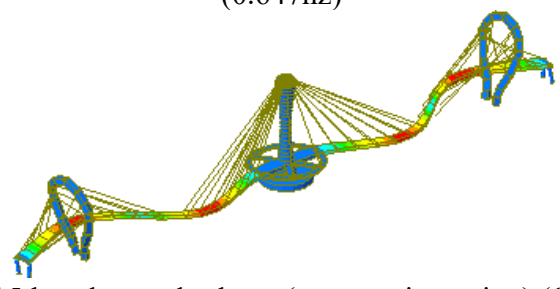

(f) 15 th order mode shape (symmetric torsion) $(1.389 \mathrm{hz})$

Figure 7. Typical dynamic modes

According to the modal analysis results, the first mode is antisymmetric vertical bending with frequency of $0.587 \mathrm{hz}$; the second mode is antisymmetric lateral bending of duck egg arch bridge tower with frequency of $0.596 \mathrm{hz}$; the fifth mode is antisymmetric lateral bending mode with frequency of $0.647 \mathrm{~Hz}$ and the first torsional frequency of $1.389 \mathrm{~Hz}$ ( 15 order). The analysis shows that the vibration modes of the bridge are dense, and obvious mode grouping phenomenon appears. The torsion frequency of the bridge is large, and the torsion to bending frequency ratio is 2.37 , which indicates that the spatial stiffness of the bridge is good.

\section{Conclusion}

(1) The traditional portal pylon structure of cable-stayed bridge is reformed. The middle tower adopts the tower structure of sightseeing tower, and the tower on both sides adopts the duck egg shaped arch tower as the tower structure of the cable-stayed bridge. The three tower cable-stayed bridge with pedestrian landscape in Lake View Park is built with beautiful appearance, leisure buildings are set on the bridge deck, flowers and plants are planted on the bridge deck, and ecological protection is achieved.
(2) The large-scale giant sightseeing tower tower tower structure improves the middle tower stiffness, effectively improves the structural stiffness of the three tower cable-stayed bridge, solves the weak tower effect problem of the traditional single column middle tower structure, and reduces the deflection deformation under the adverse live load arrangement. The sightseeing tower structure and the cable-stayed bridge tower structure are combined into one, and the two have good matching.

(3) Under the action of vertical full distributed live load, the maximum displacement in the main span is $0.231 \mathrm{~m}$, and the maximum stress of stay cable is 541.7 $\mathrm{MPa}$, which meets the requirements of the code. Under the unfavorable live load, the maximum vertical displacement in the middle of the main span is $0.261 \mathrm{~m}$, the horizontal displacement of the middle tower is $0.018 \mathrm{M}$ (the horizontal displacement of the middle tower is very small), and the maximum stress of stay cable is 584.4 The analysis shows that the vertical displacement and deformation in the middle span of the bridge under unfavorable layout live load and full distributed live load are almost the same. The middle tower structure of the bridge adopts large-scale giant sightseeing tower tower tower structure, which can avoid the weak tower effect of the tower structure of the three tower cable-stayed bridge.

(4) According to the results of modal analysis, the first mode is antisymmetric vertical bending with frequency of $0.587 \mathrm{~Hz}$; the second mode is antisymmetric lateral bending of duck egg arch bridge tower with frequency of $0.596 \mathrm{hz}$; the fifth mode is antisymmetric lateral bending mode with frequency of $0.647 \mathrm{~Hz}$ and the first torsional frequency of $1.389 \mathrm{~Hz}$ (15 order). The analysis shows that: the vibration modes are dense and obvious mode grouping phenomenon occurs. The torsion frequency of the bridge is large, and the torsion to bending frequency ratio reaches 2.37 , which indicates that the spatial stiffness of the bridge is good.

\section{References}

1. M. Kuo, \& M. Xiao-Lan, Towards a landscapeapproach bridge design: Philosophy and practice[C]. 2011 International Conference on Electric Technology and Civil Engineering (ICETCE), 2011,7102-7106.

2. Lian Q, Yuan W C. The Concept of Harmony in Aesthetics of Urban Landscape Bridge[C]// International Conference on Measuring Technology \& Mechatronics Automation. IEEE Computer Society, 2018:81-85.

3. L. Xiaotian. Design of pedestrian landscape bridge in Nanxun Jinxiang Lake Park [J]. World bridge, 2013,41 (3): 33-37

4. W. Rui, H. Dazhang, Z. Yanfeng. Mechanical analysis of steel and concrete mixed tower of Nanjing Qingao landscape bridge [J]. Shanghai highway, 2017(04):21-24+27+4.

5. Okamoto, Y., \& Nakamura, S. Static and seismic studies on steel/concrete hybrid towers for multi-span 
cable-stayed bridges[J]. Journal of Constructional Steel Research, 2011,67(2).

6. Y. Yong, L. Junqing. Design parameter analysis of three tower cable stayed bridge [J]. World bridge, 2016,44(02):53-57.

7. Vladimír, Š., Michal, P., \& Tomáš, P. A Dynamic Analysis of the Cable-Stayed Footbridge in Čelákovice Town[J]. Procedia Engineering, 2017,199, 2877-2882.

8. Pepi, C., Gioffre, , Massimiliano, Grigoriu, M. D. . Parameters identification of cable stayed footbridges using Bayesian inference[J]. Meccanica: An International Journal of Theoretical and Applied Mechanics AIMETA, 2019,54(9), 1403. 